\title{
Karakteristik Kelompok Pendukung ASI dengan Kelancaran ASI
}

\author{
Characteristics of ASI Support Groups with Smooth Breastfeeding \\ Farida Yuliani* \\ Program Studi D-III Kebidanan, Sekolah Tinggi Ilmu Kesehatan Majapahit \\ Jl. Raya Gayaman Km. 02 Mojoanyar, Mojokerto, Jawa Timur \\ *Corresponding author: farida_yuliani80@yahoo.co.id
}

\author{
Received: February 15, 2019; Revise: April 15, 2019; Accepted: May 7, 2019 \\ DOI: https://doi.org/10.31001/biomedika.v12i1.420
}

\begin{abstract}
ABSTRAK
Pemberian ASI adalah modal dasar pembentukan menjadi manusia yang berkualitas dimana proses ini dimulai sejak usia dini terutama jika ibu memberikan ASI secara eksklusif. Pemberian ASI eksklusif dilakukan sejak bayi lahir sampai bayi berusia 6 bulan tanpa diselingi makanan atau minuman yang lain. Cakupan ASI eksklusif 6 bulan di Indonesia masih jauh dari rata-rata dunia yaitu 38\% Penelitian ini bertujuan untuk mengetahui karakteristik Kelompok Pendukung Air Susu Ibu (KPASI) dengan kelancaran ASI di Desa Gayaman Kecamatan Mojoanyar. Penelitian ini menggunakan metode survey analitik dengan rancangan penelitian korelasional. Metode pengambilan data dengan pendekatan cross sectional. Populasi dalam penelitian adalah ibu menyusui yang mempunyai bayi 0-6 bulan sebanyak 25 orang. Hasil penelitian menunjukkan dari beberapa karakteristik ada 3 karakteristik yang berpengaruh terhadap kelancaran ASI, yaitu karakteristik jumlah anak, pendidikan dan sumber informasi, dimana masing-masing karateristik terdapat nilai $\mathrm{p}$ value $<0,05$. Karakteristik usia dan pekerjaan tidak berhubungan dengan kelancaran ASI. Penyuluhan dari tenaga kesehatan perlu ditingkatkan pada ibu menyusui sejak hamil terutama trimester III. Dukungan dari pihak keluarga dan lingkungan juga diperlukan agar ibu menyusui merasa tenang, nyaman selama proses penyusui berlangsung.
\end{abstract}

Kata kunci: kelompok pendukung ASI; kelancaran ASI

\section{ABSTRACT}

Giving ASI is the basic capital of forming a quality human being where this process starts at an early age, especially if the mother gives her ASI exclusively. Exclusive breastfeeding is carried out from birth to a 6 month old baby without other food or drinks. The coverage of exclusive 6 months breastfeeding in Indonesia is still far from the world average of 38\%. This study aims to determine the characteristics of KP-ASI with the smooth operation of breast milk in Gayaman Village, Mojoanyar District. This study uses analytical survey methods with a correlational research design. Data collection method with cross sectional approach. The population in the study were breastfeeding mothers who had babies 0-6 months as many as 25 people. The results showed that from several characteristics there were 3 characteristics that influence the smoothness of breastfeeding, namely the characteristics of the number of children, education and sources of information, where each 
characteristic had a value of $p$ value $<0.05$. While the characteristics of age and work are not related to the smooth operation of breast milk. Counseling from health workers needs to be improved in nursing mothers since pregnancy, especially in the third trimester. Support from the family and the environment is also needed so that nursing mothers feel calm, comfortable during the nursing process.

Keywords: ASI support group; smooth breastfeeding

\section{PENDAHULUAN}

Pemberian ASI adalah modal dasar pembentukanmenjadi manusia yang berkualitas dimana proses ini dimulai sejak usia dini terutama jika ibu memberikan ASI secara eksklusif. Pemberian ASI eksklusif dilakukan sejak bayi lahir sampai bayi berusia 6 bulan tanpa diselingi makanan atau minuman yang lain (Scholichah, 2017)

Pada tahun 2000 Menteri Negara Pemberdayaan Perempuan memberikan kebijakan tentang program peningkatan pemberian ASI di Indonesia. Presiden pada tahun tersebut menetapkan 80\% Sedangkan cakupan ASI eksklusif 6 bulan di Indonesia masih jauh dari rata-rata dunia yaitu 38\% (Depkes, 2011)

Faktor yang secara langsung dan tidak langsung menyebabkan ketidakberhasilan pemberian ASI eksklusif adalah adanya stigma dan stereotipe bahwa menyusui adalah tugas perempuan, serta kurangnya dukungan baik dari suami maupun keluarga. Pendidikan, pekerjaan, informasi petugas kesehatan juga merupakan faktor yang dapat mempengaruhi pemberian ASI eksklusif (Oktalina dkk, 2016).

Melalui kelompok pendukung ASI (KP-ASI) diharapkan ikut memberikan dukungan dalam tercapainya keberhasilan cakupan ASI eksklusif, dimana ibu menyusui akan merasa tenang, nyaman karena mendapat dukungan dari lingkungan sekitar termasuk suami dan keluarga. Perencanaan pemberian ASI bisa dilakukan sejak awal sehingga kelancaran dan pencapaian ASI eksklusif bisa terlaksana dengan baik. (Yuniyanti, 2017)

Berdasarkan latar belakang di atas penulis tertarik untuk meneliti karakteristik kelompok pendukung ASI dengan kelancaran ASI pada Ibu menyusui di Desa Gayaman Kecamatan Mojoanyar Mojokerto.

\section{METODE PENELITIAN}

Penelitian ini menggunakan metode survey analitik dengan rancangan penelitian korelasional. Metode pengambilan data dengan pendekatan cross sectional (Notoatmodjo, 2010). Populasi dalam penelitian adalah Ibu menyusui yang mempunyai bayi 0-6 bulan yang sudah mengikuti KP-ASI pada saat kehamilan TM III yaitu sebanyak 25 orang.

\section{HASIL DAN PEMBAHASAN}

Berdasarkan tabel 1 bahwa sebagian besar responden berpendidikan tinggi yaitu 16 orang $(64 \%)$. 
Tabel 1. Distribusi karakteristik responden berdasarkan pendidikan

\begin{tabular}{clcc}
\hline & Pendidikan & Frekuensi & \% \\
No & & & \\
\hline 1 & Rendah & 9 & 36 \\
2 & Tinggi & 16 & 64 \\
\hline & Total & 25 & 100 \\
\hline
\end{tabular}

Berdasarkan tabel 2 bahwa rata-rata responden berusia $<20$ tahun yaitu sebanyak 14 orang $(56 \%)$.

Tabel 2. Distribusi karakteristik responden berdasarkan umur

\begin{tabular}{cccc}
\hline No & Usia & Frekuensi & \% \\
\hline 1 & $<20$ tahun & 14 & 56 \\
2 & $20-35$ tahun & 11 & 44 \\
\hline \multicolumn{2}{l}{ Total } & 25 & 100 \\
\hline
\end{tabular}

Berdasarkan tabel 3 bahwa sebagian besar responden bekerja yaitu sebanyak 18 orang $(72 \%)$

Tabel 3. Distribusi karakteristik responden berdasarkan pekerjaan

\begin{tabular}{cccc}
\hline No & Pekerjaan & Frekuensi & \% \\
\hline 1 & Bekerja & 18 & 72 \\
2 & Tidak & 7 & 28 \\
& bekerja & & \\
\hline \multicolumn{2}{c}{ Total } & 25 & 100 \\
\hline
\end{tabular}

Berdasarkan tabel 4 bahwa sebagian besar responden memiliki jumlah anak 2-4 yaitu sebanyak 19 orang $(76 \%)$.

Tabel 4. Distribusi karakteristik responden berdasarkan jumlah anak

\begin{tabular}{cccc}
\hline No & $\begin{array}{c}\text { Jumlah } \\
\text { Anak }\end{array}$ & Frekuensi & \% \\
\hline 1 & 1 & 6 & 24 \\
2 & $2-4$ & 19 & 76 \\
\hline & Total & 25 & 100 \\
\hline
\end{tabular}

Berdasarkan tabel 5 bahwa sebagian besar informasi yang diterima responden berasal dari tenaga kesehatan yaitu 21 orang $(84 \%)$.

Tabel 5. Distribusi karakteristik responden berdasarkan sumber informasi

\begin{tabular}{clcc}
\hline No & $\begin{array}{c}\text { Sumber } \\
\text { Informasi }\end{array}$ & Frekuensi & $\begin{array}{c}\text { Prosent } \\
\text { ase }\end{array}$ \\
\hline 1 & Medis & 21 & 84 \\
2 & Non Medis & 4 & 16 \\
\hline & Total & 25 & 100 \\
\hline
\end{tabular}

Tabel 6. Tabulasi silang Distribusi frekuensi jumlah anak dengan kelancaran ASI

\begin{tabular}{|c|c|c|c|c|c|}
\hline \multicolumn{6}{|c|}{ Chi-Square Tests } \\
\hline & Value & $\mathrm{df}$ & $\begin{array}{l}\text { Asymp. } \\
\text { Sig. (2- } \\
\text { sided) }\end{array}$ & $\begin{array}{l}\text { Exact } \\
\text { Sig. (2- } \\
\text { sided) }\end{array}$ & $\begin{array}{c}\text { Exact } \\
\text { Sig. (1- } \\
\text { sided) }\end{array}$ \\
\hline $\begin{array}{l}\text { Pearson } \\
\text { Chi-Square }\end{array}$ & $5.855^{\mathrm{a}}$ & 1 & .016 & & \\
\hline $\begin{array}{l}\text { Continuity } \\
\text { Correction }^{\mathrm{b}}\end{array}$ & 3.603 & 1 & .058 & & \\
\hline $\begin{array}{l}\text { Likelihood } \\
\text { Ratio }\end{array}$ & 5.435 & 1 & .020 & & \\
\hline $\begin{array}{l}\text { Fisher's } \\
\text { Exact Test }\end{array}$ & & & & .032 & .032 \\
\hline $\begin{array}{l}\text { Linear-by- } \\
\text { Linear } \\
\text { Association }\end{array}$ & 5.621 & 1 & .018 & & \\
\hline $\begin{array}{l}\mathrm{N} \text { of Valid } \\
\text { Cases }\end{array}$ & 25 & & & & \\
\hline
\end{tabular}

Setelah dilakukan analisa data beberapa karakteristik tidak menunjukkan pengaruh terhadap kelancaran ASI. Hubungan karakteristik Jumlah anak dengan kelancaran ASI. Dari tabel 4 terlihat sebagian besar (76\%) memiliki jumlah anak antara 2-4. Paritas merupakan jumlah anak hidup yang sudah dilahirkan oleh seorang ibu.Ibu yang mempunyai anak lebih dari satu mempunyai pengalaman sebelumnya dalam memberikan ASI sehingga mereka juga 
punya banyak pengalaman bagaimana menetukan kelancaran ASI. Ibu yang mempunyai anak 2-4 mempunyai kemungkinan kesempatan lebih banyak memberikan ASI dibandingkan dengan ibu yang tidak mempunyai anak sejumlah itu. Berdasarkan hasil tabulasi silang didapatkan nilai $\mathrm{p}$ value $<0,05$ sehingga terhadap hubungan antara jumlah anak atau paritas dengan kelancaran ASI. Pengalaman dalam hal menyusui ibu juga mampu menyiasati bagaimana cara mempertahankan kelancaran ASI.

Tabel 7. Tabulasi silang Distribusi frekwensi pendidikan dengan kelancaran ASI

\begin{tabular}{|c|c|c|c|c|c|}
\hline \multicolumn{6}{|c|}{ Chi-Square Tests } \\
\hline & Value & $\mathrm{df}$ & $\begin{array}{l}\text { Asymp. } \\
\text { Sig. (2- } \\
\text { sided) }\end{array}$ & $\begin{array}{l}\text { Exact } \\
\text { Sig. (2- } \\
\text { sided) }\end{array}$ & $\begin{array}{l}\text { Exact } \\
\text { Sig. (1- } \\
\text { sided) }\end{array}$ \\
\hline $\begin{array}{l}\text { Pearson } \\
\text { Chi-Square }\end{array}$ & $10.429^{\mathrm{a}}$ & 1 & .001 & & \\
\hline $\begin{array}{l}\text { Continuity } \\
\text { Correction }^{\mathrm{b}}\end{array}$ & 7.648 & 1 & .006 & & \\
\hline $\begin{array}{l}\text { Likelihood } \\
\text { Ratio }\end{array}$ & 10.709 & 1 & .001 & & \\
\hline $\begin{array}{l}\text { Fisher's } \\
\text { Exact Test }\end{array}$ & & & & .003 & .003 \\
\hline $\begin{array}{l}\text { Linear-by- } \\
\text { Linear } \\
\text { Association }\end{array}$ & 10.012 & 1 & .002 & & \\
\hline $\begin{array}{l}\mathrm{N} \text { of Valid } \\
\text { Cases }\end{array}$ & 25 & & & & \\
\hline
\end{tabular}

Tabel 8. Tabulasi silang Distribusi frekwensi sumber informasi dengan kelancaran ASI

\begin{tabular}{lccccc}
\hline \multicolumn{5}{c}{ Chi-Square Tests } \\
\hline & Value & df & $\begin{array}{r}\text { Asymp. } \\
\text { Sig. (2- } \\
\text { sided) }\end{array}$ & $\begin{array}{r}\text { Exact } \\
\text { Sig. (2- } \\
\text { sided) }\end{array}$ & $\begin{array}{r}\text { Exact } \\
\text { Sig. (1- } \\
\text { sided) }\end{array}$ \\
\hline $\begin{array}{l}\text { Pearson Chi- } \\
\text { Square }\end{array}$ & $5.218^{\mathrm{a}}$ & 1 & .022 \\
\hline $\begin{array}{l}\text { Continuity } \\
\text { Correction }\end{array}$ & 2.811 & 1 & .094 & \\
\hline $\begin{array}{l}\text { Likelihood } \\
\text { Ratio }\end{array}$ & 4.699 & 1 & .030 \\
\hline
\end{tabular}

\begin{tabular}{|c|c|c|c|c|c|}
\hline $\begin{array}{l}\text { Fisher's Exact } \\
\text { Test }\end{array}$ & & & & .053 & .053 \\
\hline $\begin{array}{l}\text { Linear-by- } \\
\text { Linear } \\
\text { Association }\end{array}$ & 5.009 & 1 & .025 & & \\
\hline $\begin{array}{l}\mathrm{N} \text { of Valid } \\
\text { Cases }\end{array}$ & 25 & & & & \\
\hline
\end{tabular}

Tabel 9. Tabulasi silang Distribusi frekwensi usia dengan kelancaran ASI

\begin{tabular}{|c|c|c|c|c|c|}
\hline \multicolumn{6}{|c|}{ Chi-Square Tests } \\
\hline & Value & df & $\begin{array}{l}\text { Asymp. } \\
\text { Sig. (2- } \\
\text { sided) }\end{array}$ & $\begin{array}{l}\text { Exact } \\
\text { Sig. (2- } \\
\text { sided) }\end{array}$ & $\begin{array}{l}\text { Exact } \\
\text { Sig. (1- } \\
\text { sided) }\end{array}$ \\
\hline $\begin{array}{l}\text { Pearson Chi- } \\
\text { Square }\end{array}$ & $3.484^{\mathrm{a}}$ & 1 & .062 & & \\
\hline $\begin{array}{l}\text { Continuity } \\
\text { Correction }^{\mathrm{b}}\end{array}$ & 2.010 & 1 & .156 & & \\
\hline $\begin{array}{l}\text { Likelihood } \\
\text { Ratio }\end{array}$ & 3.824 & 1 & .051 & & \\
\hline $\begin{array}{l}\text { Fisher's Exact } \\
\text { Test }\end{array}$ & & & & .090 & .076 \\
\hline $\begin{array}{l}\text { Linear-by- } \\
\text { Linear } \\
\text { Association }\end{array}$ & 3.344 & 1 & .067 & & \\
\hline $\begin{array}{l}\mathrm{N} \text { of Valid } \\
\text { Cases }\end{array}$ & 25 & & & & \\
\hline
\end{tabular}

Tabel 10. Tabulasi silang Distribusi frekwensi pekerjaan dengan kelancaran ASI

\begin{tabular}{|c|c|c|c|c|c|}
\hline \multicolumn{6}{|c|}{ Chi-Square Tests } \\
\hline & Value & $\mathrm{df}$ & $\begin{array}{l}\text { Asymp. } \\
\text { Sig. (2- } \\
\text { sided) }\end{array}$ & $\begin{array}{l}\text { Exact } \\
\text { Sig. (2- } \\
\text { sided) }\end{array}$ & $\begin{array}{l}\text { Exact } \\
\text { Sig. (1- } \\
\text { sided) }\end{array}$ \\
\hline $\begin{array}{l}\text { Pearson Chi- } \\
\text { Square }\end{array}$ & $3.781^{\mathrm{a}}$ & 1 & .052 & & \\
\hline $\begin{array}{l}\text { Continuity } \\
\text { Correction }^{\mathrm{b}}\end{array}$ & 2.098 & 1 & .148 & & \\
\hline $\begin{array}{l}\text { Likelihood } \\
\text { Ratio }\end{array}$ & 5.591 & 1 & .018 & & \\
\hline $\begin{array}{l}\text { Fisher's Exact } \\
\text { Test }\end{array}$ & & & & .133 & .066 \\
\hline $\begin{array}{l}\text { Linear-by- } \\
\text { Linear } \\
\text { Association }\end{array}$ & 3.630 & 1 & .057 & & \\
\hline $\begin{array}{l}\mathrm{N} \text { of Valid } \\
\text { Cases }\end{array}$ & 25 & & & & \\
\hline
\end{tabular}

Hubungan antara karakteristik pendidikan dengan kelancaran ASI. Dari tabel 1 terlihat sebagian besar memiliki pendidikan tinggi yaitu 16 orang (64\%). 
Dari hasil tabulasi silang juga didapatkan nilai kemaknaan $p$ value $<0,05$ artinya terdapat hubungan antara pendidikan dan kelancaran ASI. Seseorang yang memiliki pendidikan tinggi akanmerasa terdorong untuk kritis mencari tahu pengalaman dan untuk mengembangkan pengalaman sehingga informasi yang diterima akan menjadi pengetahuan. Pendidikan yang tinggi membuat seorang ibu lebih berfikir rasional dan kritis dalam mengetahui kegunaan ASI, Pendidikan tinggijuga lebih mudah menerima informasi baru dibandingkan dengan seseorang yang berpendidikan rendah. Pendidikan juga merupakan faktor yang berkaitan dengan terbukanya akses ibu untuk bekerja (Unbegku, 2013).

Hubungan karakteristik sumber informasi dengan kelancaran ASI. Dari tabel 5 terlihat sebagian besar responden mendapatkan informasi dari tenaga kesehatan sebanyak 21 orang (84\%). Responden yang mendapat informasi tentang pentingnya ASI dari petugas kesehatan akan terdorong untuk memberikan ASI secara eksklusif dibandingkan dengan yang tidak pernah mendapatkan informasi dari petugas kesehatan.Berdasarkan tabulasi silang didapatkan kemaknaan $p$ value $<0,05$ sehingga terdapat hubungan antara sumber informasi dengan kelancaran ASI.

Yunianti (2017) menyatakan bahwa ada hubungan antara peran petugas kesahatan dengan pemberian ASI eksklusif. Soetjaningsih juga menyatakan bahwa ada faktor lain yang mempengaruhi pemberian ASI yaitu kurangnya petugas kesehatan yang memberikan informasi mengenai ASI sehingga masyarakat kurang mendapat informasi atau dorongan tentang ASI eksklusif.

Petugas kesehatan yang secara aktif dan kontinu memberikan penyuluhan tentang ASI sejak kehamilan akan memberikan motivasi tersendiri bagi ibu menyusui dalam merencanakan pemberian ASI sejak dini, proses ini akan berpengaruh terhadap kelancaran ASI pada ibu. Petugas kesehatan merupakan salah satu faktor penentu keberhasilan dan kelancaran ASI. (Nuzulia, 2013).

Beberapa karakteristik tidak terdapat hubungan dengan kelancaran ASI, hal ini disebabkan beberapa mitos masih berkembang dilingkungan penelitian misalnya pola makan yang dibatasi selama masa nifas berlangsung.

\section{KESIMPULAN}

Terdapat beberapa karakteristik KPASI yang memberikan pengaruh terhadap kelancaran ASI yaitu pendidikan, jumlah anak serta sumber informasi namun ada beberapa karateristik yaitu usia dan pekerjaan yang tidak memberikan pengaruh terhadap kelancaran ASI, hal ini bisa dipengaruhi oleh mitos dan kepercayaan yang berada dilingkungan setempat.

\section{DAFTAR PUSTAKA}

Asih, Y, dan Risneni, 2016. Asuhan kebidanan Nifas dan Menyusui, Jakarta, Trans Info Media.

Dinas Kesehatan Kab. Mojokerto, 2011. Profil Kesehatan Propinsi Jawa Timur.

Fikawati, S. dan Syafiq, A. 2009. Penyebab Keberhasilan dan Kegagalan Praktik Pemberian ASI Eksklusif. Kesmas: 
National Public Health Journal 4 (3): 120131.

Kamariyah, N. 2017. Kondisi Psikologi Mempengaruhi Produksi Asi Ibu Menyusui di Bps Aski Pakis Sido Kumpul Surabaya. Journal of Health Sciences 7 (1): 29-36.

Kusumayanti, N. dan Nindya, T.S. 2018 Hubungan Dukungan Suami Dengan Pemberian Asi Eksklusif di Daerah Perdesaan. Media Gizi Indonesia 12 (2): 98-106.

Notoadmodjo S., 2010. Metodologi Penelitian Kesehatan, Jakarta, Rineka Cipta.

Nugrahaeni, S. A., dan Margawati, A. 2014 Pengaruh Modul Terhadap Peningkatan Pengetahuan, Sikap Dan Praktek Kader Dalam Upaya Pemberian ASI Eksklusif. Gizi Indonesia 37 (1): 19-28.

Nuzulia, F. 2013. Hubungan antara dukungan keluarga dengan pemberian ASI eksklusif pada bayi di Desa Bebengan Kecamatan Boja Kabupaten Kendal." Jurnal Keperawatan Maternitas 1 (1): 1-8.

Oktalina, O., Muniroh, L., and Adiningsih, S.2016. Hubungan dukungan suami dan dukungan keluarga dengan pemberian asi eksklusif pada ibu anggota kelompok pendukung asi (KP-ASI). Media Gizi Indonesia 10 (1).

Puspita, Y. A. 2015. Perbedaan Persepsi Kontrol Diri Ibu Hamil Terhadap Intensi Ibu Untuk Memberikan ASI Eksklusif Pada Kelas Ibu
Hamil Plus di Puskesmas Muara Teweh Kabupaten Barito Utara. Eduhealth 5 (2): 123-130.

Ramadani, Mery, and Ella Nurlaella Hadi. 2010. Dukungan Suami Dalam Pemberian Asi Eksklusif Di Wilayah Kerja Puskesmas Air Tawar Kota Padang, Sumatera Barat. Kesmas: National Public Health Journal 4 (6)

Scholichah, N. 2012. Hubungan Perawatan Payudara Pada Ibu Postpartum Dengan Kelancaran Pengeluaran Asi Di Desa Karang Duren Kecamatan Tengaran Kabupaten Semarang. Jurnal Komunikasi Kesehatan (Edisi 3) P3M. 2 (2): 1-7

Sugiarti E, Zulaekah S., \& Puspowati D.S, Faktorfaktor yang berhubungan dengan pemberian ASI eksklusif di Kecamatan Karang Malang

Suryani, P dan Handayani I. 2018. Senam hamil dan ketidaknyamanan Ibu Hamil Trimester tiga. Jurnal Bidan IV(1): 33-39.

Unbegku and Anyika. 2013. Influence of maternal Characteristics on Ecclusive breastfeeding practice among urban mother in umuahia Nigeria. Mal J Nutr 19 (3) 311-323.

Yuniyanti, B. 2017. Efektivitas Kelompok Pendukung Asi (KP-ASI) Eksklusif terhadap Perilaku Pemberian Asi Eksklusif. Jurnal Ilmiah Bidan 2 (1): 41-47. 